Research Paper

\title{
The effect of repetitive exposure to intravenous anesthetic agents on the immunity in mice
}

\author{
Hyun Jun Park' ${ }^{1}$, Liyun Piao', Eun-Hye Seo ${ }^{2}$, Seung Hyun Lee ${ }^{3,4^{*}}$, Seong-Hyop Kim ${ }^{1,4,5^{*} \bowtie}$ \\ 1. Department of Infection and Immunology, Konkuk University School of Medicine, Seoul, Korea. \\ 2. BK21 plus, Department of Cellular and Molecular Medicine, Konkuk University School of Medicine, Seoul, Korea. \\ 3. Department of Microbiology, Konkuk University School of Medicine, Seoul, Korea. \\ 4. Department of Medicine, Institute of Biomedical Science and Technology, Konkuk University School of Medicine, Seoul, Korea. \\ 5. Department of Anesthesiology and Pain medicine, Konkuk University Medical Center, Konkuk University School of Medicine, Seoul, Korea. \\ *The two authors evenly contributed to the study as corresponding author.
}

$\triangle$ Corresponding author: Seong-Hyop Kim, M.D., Ph.D., Address: Department of Anesthesiology and Pain medicine, Konkuk University Medical Center, Konkuk University School of Medicine, 120-1 Neudong-ro (Hwayang-dong), Gwangin-gu, Seoul 05030, Korea. Tel: +82-2-2030-5454; Fax: +82-2-2030-5449; E-mail: yshkim75@daum.net

(C) The author(s). This is an open access article distributed under the terms of the Creative Commons Attribution License (https://creativecommons.org/licenses/by/4.0/). See http://ivyspring.com/terms for full terms and conditions.

Received: 2019.11.07; Accepted: 2020.01.13; Published: 2020.02.04

\begin{abstract}
Introduction: This study was designed to assess the effect of repetitive exposure to intravenous anesthetic agents on the immunity in mice.

Materials and Methods: The mice were divided into six groups: three intravenous anesthetic agents groups (dexmedetomidine, midazolam and propofol groups), and three corresponding control groups ( $C_{D}, C_{M}$, and $C_{P}$ groups). The intravenous injections were administered once per day for 5 days. The immunity of mice was checked after the last intravenous injection. Histopathology and immunochemistry of liver and kidneys were evaluated. Cytokine levels in the blood was also checked. vs. evaluated with cytokine levels in the blood.

Results: Cluster of differentiation (CD)4+ $T$ cells were significantly less expressed in dexmedetomidine and propofol groups, compared with the corresponding control groups [34.08 $\pm 5.63 \%$ in the dexmedetomidine group vs. $59.74 \pm 8.64 \%$ in the $C_{D}$ group, $p<0.05 ; 25.28 \pm 7.28 \%$ in the propofol group vs. $61.12 \pm 2.70 \%$ in the $C_{p}$ group, $\left.p<0.05\right]$. Apoptosis of CD4+ $T$ cells was increased significantly in dexmedetomidine and propofol groups, compared with the corresponding control groups. Histopathological findings of liver and kidneys did not show any specific differences of any of three intravenous anesthetic agents groups with their corresponding control groups, although immunohistochemical examination indicated significantly lower expression of Toll-like receptor-4 from liver and kidneys in dexmedetomidine and propofol groups. The cytokine levels were not different between the groups.
\end{abstract}

Conclusion: Repetitive exposure to dexmedetomidine and propofol reduced the expression of CD4+ $\mathrm{T}$ cells but did not induce any significant liver or kidney injuries.

Key words: intravenous anesthetic agent, dexmedetomidine, midazolam, propofol, immunity

\section{Introduction}

Sedation is widely performed in clinical situations to facilitate diagnostic and therapeutic procedures. The most commonly used intravenous anesthetic agents for sedation are dexmedetomidine, midazolam, and propofol. The action of sedation is expressed via $\mathrm{a}_{2}$-adrenergic receptors for dexmedetomidine and $\gamma$-aminobutyric acid (GABA) receptors for midazolam and propofol (1-4). Both $\mathrm{a}_{2}$-adrenergic receptors $(5,6)$ and GABA receptors $(7-9)$ modulate neurotransmitters and influence the immune system $(10,11)$. Repeated sedation for a short time is sometimes performed on the basis of patient statusfor example, pediatric patients. Depending on the intravenous anesthetic agents used, different 
immunity patterns would be expected. However, this topic has not yet been investigated.

We hypothesized that repeated exposure to anesthetic agents might affect the immunity differently, depending on the intravenous anesthetic agent administered. This study was designed to assess the effect of 5 days of repetitive exposure to intravenous anesthetic agents, including dexmedetomidine, midazolam, and propofol, on the immunity in mice.

\section{Materials and Methods}

These experiments were approved by the Institutional Animal Care and Use Committee (IACUC) of the Konkuk University (KU16126) and conducted at the Konkuk University Laboratory Animal Research Center. The experiments were performed by following the IACUC guidelines for studying laboratory animals.

The data used to support the findings of the study are available from the corresponding author (Seong-Hyop Kim, yshkim75@daum.net) upon request.

Six-week-old male BALB/c mice (weight $20 \mathrm{~g}$ ) were used for the experiment. The animals were quarantined for 2 weeks to confirm that they were pathogen-free. The mice were divided into six groups: three intravenous anesthetic agents groups (dexmedetomidine, midazolam, and propofol groups) and three corresponding control groups $\left(C_{D}\right.$ group for dexmedetomidine, $C_{M}$ for midazolam, and $C_{P}$ for propofol).

\section{Anesthetic method}

The mice were placed in a clean dry cage without bedding before anesthesia, to avoid ingestion or inhalation during the procedure. The mice were maintained in room air at $25^{\circ} \mathrm{C}$ throughout the procedure to prevent hypothermia. Dexmedetomidine $(0.4 \mathrm{mg} / \mathrm{kg}$; Dexmedine inj., Hana Pharm, Seoul, Korea) midazolam (50 mg/kg Vascam inj.; Hana Pharm), propofol (26 mg/kg Anepol inj.; Hana Pharm) and normal saline for the corresponding control groups were intravenously injected through the tail vein (12-14). One milliliter was administered to animals in all groups. The mice were laid in the supine position in a V-shaped trough. The hypnotic response was confirmed by loss of the righting reflex (LORR). The LORR was defined as the inability of the mice to right themselves. The induction time from injection of the study drug to LORR was recorded. When the mice righted themselves after LORR, they were laid in the supine position again. Recovery of the righting reflex was defined as the ability of the mice to right themselves twice within $60 \mathrm{~s}$. LORR duration was defined as the time interval between loss and recovery of the righting response. The sedated mice were carefully observed to check for any complications. A radiant heating lamp was applied to maintain body temperature during the procedure. The intravenous injections were administered once per day for 5 days. All procedures were performed by the same investigator at the same time. Respiration rate was observed during all procedures. Body temperature was monitored with a rectal thermometer and maintained above $36^{\circ} \mathrm{C}$. The mice were euthanized by cervical dislocation immediately after the last intravenous injection. Immune cells undergoing apoptosis in the blood were checked by flow cytometry to evaluate the immunity. Histopathology and immunochemistry of the liver and kidney were also performed. We checked blood cytokine levels by enzyme-linked immunosorbent assay (ELISA).

\section{Peripheral blood mononuclear cells (PBMCs)}

After excising the spleen, the diaphragm was incised and the heart exposed. Blood samples were obtained from heart punctures using heparin-coated 2 $\mathrm{ml}$ syringes and collected in $1.5 \mathrm{ml}$ Eppendorf tubes (Sigma Aldrich, St. Louis, MO, USA). The whole blood was centrifuged at 3,000 rpm for $5 \mathrm{~min}$ to separate the serum. The serum samples were isolated and saved in another $1.5 \mathrm{ml}$ tube at $-20^{\circ} \mathrm{C}$ to check the cytokine levels. The remaining blood was diluted in phosphate-buffered saline (PBS) to prevent coagulation, and PBMCs were separated from the remaining blood by Ficoll density-gradient centrifugation at $2,400 \mathrm{rpm}$ for $20 \mathrm{~min}$ at room temperature. The PBMCs were washed in PBS and aliquoted into two 5 $\mathrm{ml}$ round-bottom tubes. They were then washed in fluorescence-activated cell sorting (FACS) buffer.

\section{Immunofluorescence staining of immune cells}

To confirm innate and adaptive immune systems, respectively, neutrophils for innate immune system, providing a rapid response, and cluster of differentiation $(\mathrm{CD}) 4^{+} \mathrm{T}$ cells, $\mathrm{CD}^{+} \mathrm{T}$ cell and $\mathrm{CD} 4{ }^{+} \mathrm{CD} 25^{+} \mathrm{T}$ cell for adaptive immune response, providing a slow but highly specific response, were chosen. They undergoing apoptosis were evaluated using isolated PBMCs.

The pellet in the $5 \mathrm{ml}$ round-bottom tube with isolated PBMCs was stained with the monoclonal antibody peridinin-chlorophyll (PerCP) CD11b (Biolegend, Dedham, MA, USA), Fluorescein isothiocyanate (FITC) Ly6G and allophycocyanin (APC) Ly6C (Biolegend) were used to check the neutrophils. The pellet in the $5 \mathrm{ml}$ round-bottom tube with isolated PBMCs was stained with PerCP CD25 (Biolegend) and APC CD4 (Biolegend) monoclonal antibodies to 
check the $\mathrm{CD}^{+}$and $\mathrm{CD} 4{ }^{+} \mathrm{CD} 25^{+} \mathrm{T}$ cells; and with PerCP CD3 (Biolegend) and APC CD8 (Biolegend) monoclonal antibodies to check the $\mathrm{CD}^{+} \mathrm{T}$ cells. The cells were incubated for $30 \mathrm{~min}$ at room temperature in the dark. The cells were washed in $500 \mu \mathrm{l}$ of cell staining buffer (Biolegend). To check for apoptosis, $300 \mu l$ of binding buffer (Biolegend) and FITC Annexin $\mathrm{V}$ (Biolegend) were added and incubated for $30 \mathrm{~min}$ in the dark at room temperature. After the incubation, the population of immune cells undergoing apoptosis was measured and analyzed with the FACS Accuri C6 flow cytometer (BD Biosciences, Seoul, Korea).

\section{Tissue preparation for histopathology and immunohistochemistry}

The order of the procedures for histopathology and immunohistochemistry was as follows: 1) tissue preparation, 2) fixation, 3) dehydration, 4) embedding, and 5) staining.

The liver and kidneys were obtained from the mice and fixed overnight at $25^{\circ} \mathrm{C}$ in a $4 \%$ paraformaldehyde solution (Biosesang, Seoul, Korea). The fixed liver was cut through the caudate and left lateral lobes. The fixed kidneys were transected. The dissected organs underwent tissue processing using a tissue processor (TP1020 ${ }^{\circledR}$; Leica Biosystems, Lincolnshire, IL, USA). The dissected organs were dehydrated through a series of graded ethanol baths to displace water and then infiltrated with wax. The organs were embedded in paraffin using an embedding center (EG1150 ${ }^{\circledR}$; Leica Biosystems). Tissue sections were cut to $4-\mu \mathrm{m}$ thickness using a microtome (Leica Biosystems) and mounted on poly-l-lysine coated microscopic slides (Mutokagaku, Tokyo, Japan).

\section{Histopathological examination}

The histopathological examination was conducted with hematoxylin and eosin-stained slides. The sections were deparaffinized and rehydrated. Then, the slides were stained with hematoxylin (Sigma-Aldrich) for $3 \mathrm{~min}$ in the dark. After staining, the slides were washed in tap water. The slides were then stained with eosin (Sigma-Aldrich) for $30 \mathrm{sec}$ and rewashed in tap water. The slides were dehydrated and cover-slipped using mounting medium and images were obtained under a microscope.

The liver injury score was defined by sinusoidal congestion, hepatocyte necrosis, and ballooning degeneration and scored from 0 to 4 : 0 , no necrosis, congestion or ballooning; 1, minimal congestion, single-cell necrosis or ballooning; 2, congestion, ballooning degeneration or lobular necrosis $<30 \%$; 3 , moderate congestion, ballooning degeneration or lobular necrosis < 60\%; 4, severe congestion, ballooning degeneration or lobular necrosis $>60 \%$.
The renal injury score was defined by the degree of tubular cell damage and ranged from 0 to 4 : 0 , no damage; 1 , unicellular or patchy isolated necrosis; 2 , tubular necrosis $<25 \%$; 3 , tubular necrosis of $25-50 \%$; $4,>50 \%$ tubular necrosis and presence of infarcted tissue.

\section{Immunohistochemical examination}

Toll-like receptor-4 (TLR4) is a transmembrane protein, and its activation leads to an intracellular signaling pathway and production of inflammatory cytokines, responsible for activating the innate immune system. Therefore, TLR4 was used to check the immunity in the tissues. The slides were deparaffinized and rehydrated. To avoid non-specific binding of antibody, the slices were incubated in blocking solution (Vector Laboratories, Burlingame, CA, USA) for $1 \mathrm{~h}$ and reacted with TLR4 rabbit polyclonal antibody (Abcam, Cambridge, UK) at a 1:100 dilution overnight at $4^{\circ} \mathrm{C}$. The slides were then washed in PBS, and the sections were incubated for 1 $h$ with biotinylated secondary goat anti-rabbit IgG (Abcam). After the incubation, the ABC Reagent (Vector Laboratories) was applied to react with the biotinylated antibody for $1 \mathrm{~h}$ at $25^{\circ} \mathrm{C}$ and attached with 3,3-diaminobenzidine reagent (Vector Laboratories). The slides were stained with hematoxylin as a counterstain, dehydrated and cover-slipped using mounting medium (Vector Laboratories). Images were obtained under a microscope (Nikon, Tokyo, Japan). TLR4 intensity was quantified using Image J software (NIH, Bethesda, MD, USA).

\section{Cytokines}

The levels of interleukin (IL)-2, interferon $(\mathrm{IFN})-\gamma$, tumor necrosis factor (TNF)- $\alpha$, and transforming growth factor (TGF)- $\beta$ were checked in serum by ELISAs.

\section{Statistical analysis}

"Resource equation method" was used to determine sample size because it was impossible to assume the effect size or no previous published studies for power analysis. With the formula for the resource equation method $(\mathrm{E}=$ Total number of animals - Total number of groups, any sample size, which keeps E between 10 and 20, should be considered to be adequate.), total number of animals between 12 and 22 for an intravenous anesthetic agent (between 36 and 66 for the three intravenous anesthetic agent including the corresponding control group) was adequate for sample size determination. Differences between groups were analyzed with the Mann-Whitney U test using GraphPad Prism software (ver. 5.01; GraphPad Software, La Jolla, CA, USA). Data are presented as means \pm standard deviation 
[median $(25-75 \%)]$. A $p$-value $<0.05$ was considered significant.

\section{Results}

A total of 36 mice were used for the experiments and evenly allocated to the six groups. No complications occurred.

The induction time and duration of LORR were longer in the dexmedetomidine group than in the other intravenous anesthetic groups (Table 1). The propofol group had the shortest LORR induction time and duration (Table 1).
No significant differences in the expression of immune cells were observed, except for $\mathrm{CD}^{+} \mathrm{T}$ cells, in any of the three intravenous anesthetic agents groups or the corresponding control groups (Figure 1). $\mathrm{CD}^{+} \mathrm{T}$ cells from PBMCs had significantly lower expression in the dexmedetomidine and propofol groups versus the corresponding control groups $[34.08 \pm 5.63 \%$ in the dexmedetomidine group vs. $59.74 \pm 8.64 \%$ in the $\mathrm{C}_{\mathrm{D}}$ group, $p<0.05 ; 25.28 \pm 7.28 \%$ in the propofol group vs. $61.12 \pm 2.70 \%$ in the $C_{p}$ group, $p<0.05$ ] (Figure 1).

A
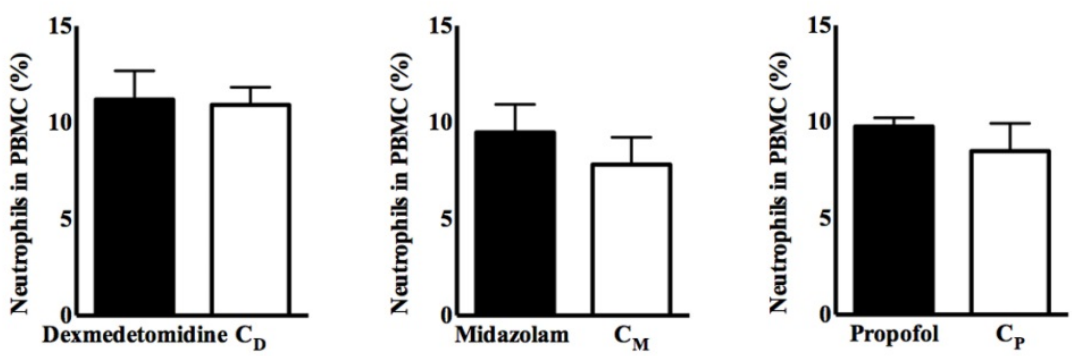

B
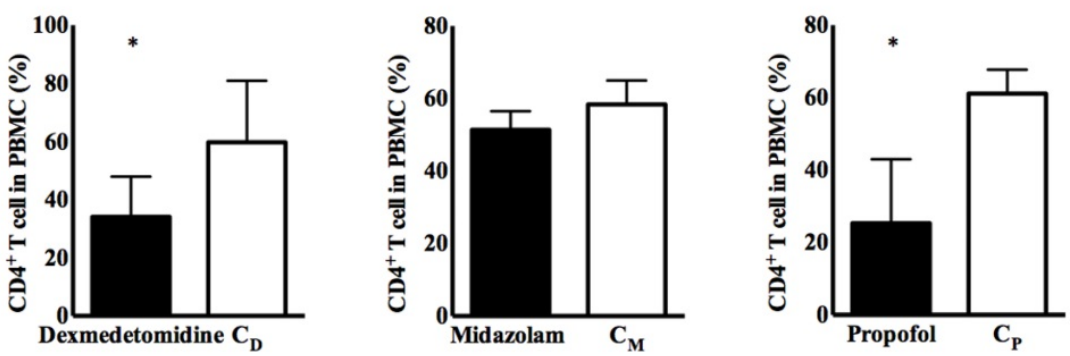

$\mathrm{C}$
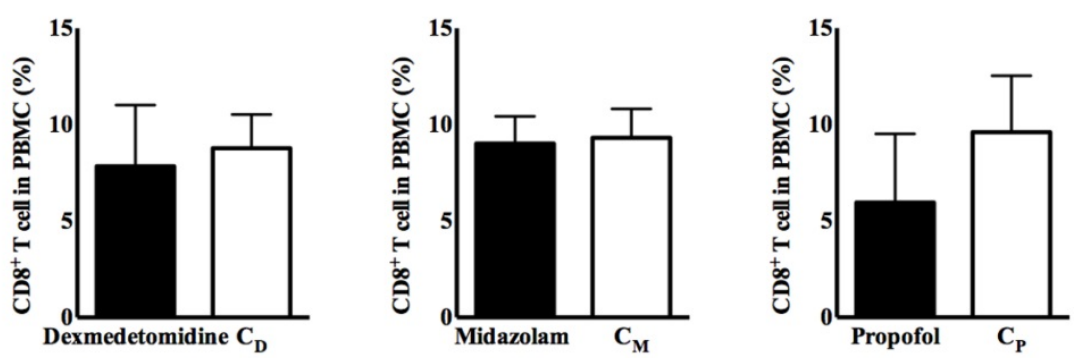

$\mathrm{D}$
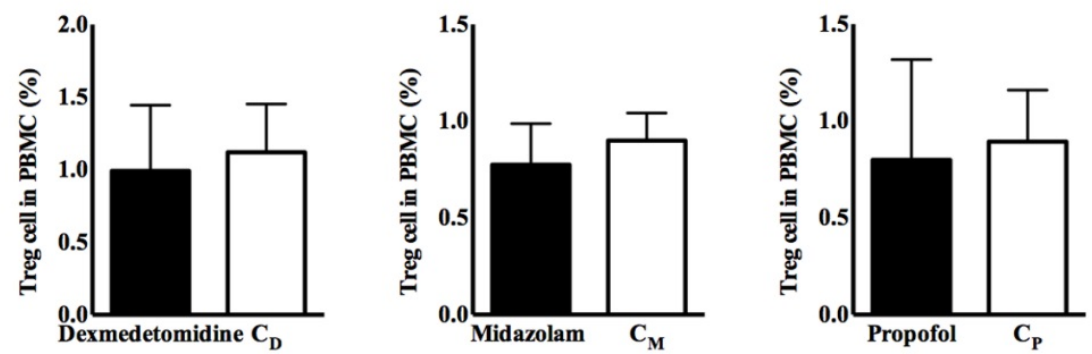

Figure 1. Expression of immune cells in peripheral blood mononuclear cells (PBMCs). (A) Neutrophils, (B) cluster of differentiation (CD) $4^{+} T$ cells, (C) $C D 8^{+} T$ cells, and (D) $C^{2}{ }^{+}{ }^{C D 25}{ }^{+} T$ cells. Abbreviations: $C_{D}$ group, corresponding control group for dexmedetomidine; $C_{M}$ group, corresponding control group for midazolam; $C_{P}$ group, corresponding control group for propofol. ${ }^{*} p<0.05$ compared with corresponding control group. 
A
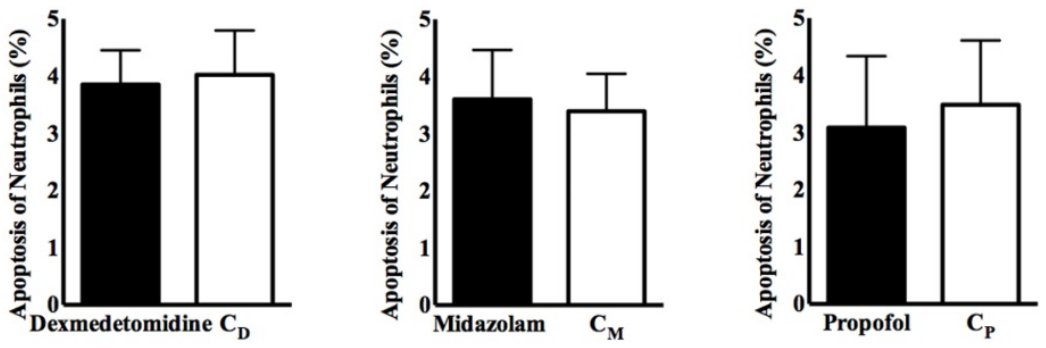

B
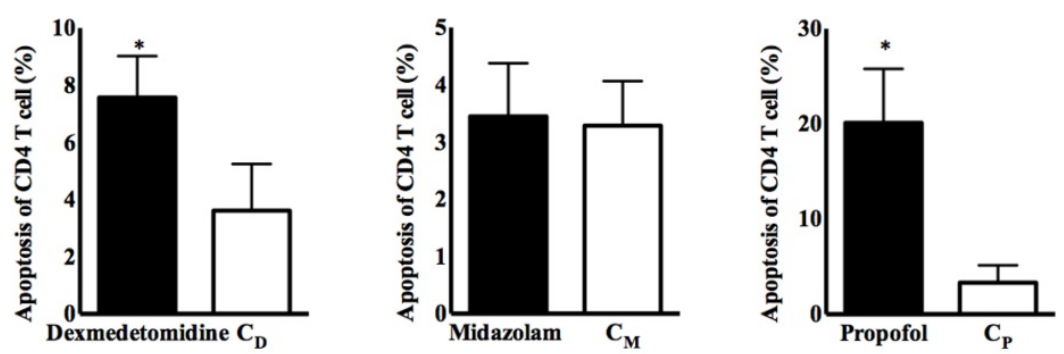

C
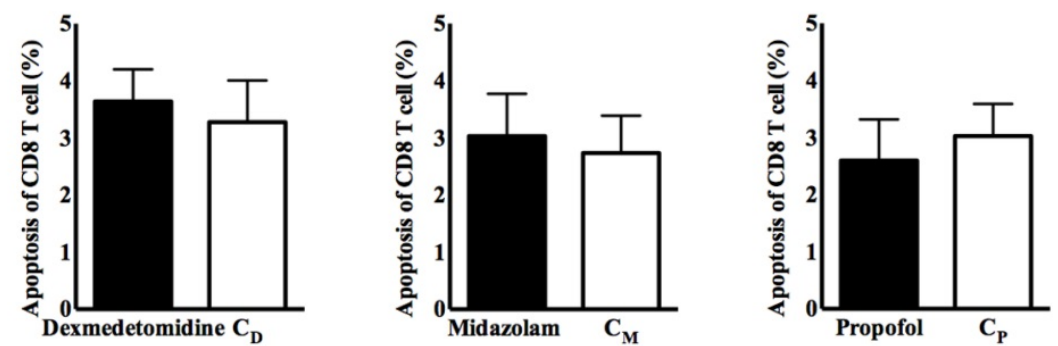

D
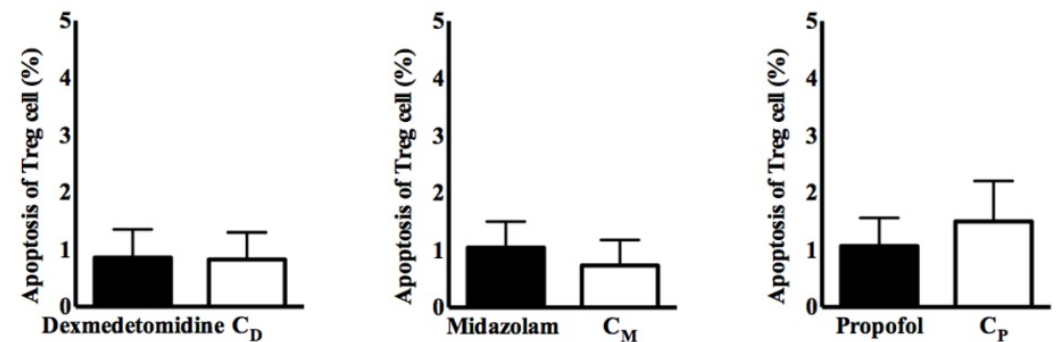

Figure 2. Apoptosis of immune cells in PBMCs. (A) Neutrophils, (B) CD4+ $T$ cells, (C) CD8 ${ }^{+} T$ cells, and (D) $C D 4+C D 25^{+} T$ cells. Abbreviations: $C_{D}$ group, corresponding control group for dexmedetomidine; $C_{M}$ group, corresponding control group for midazolam; $C_{p}$ group, corresponding control group for propofol; $C$, cluster of differentiation. ${ }^{*} p<0.05$ compared with corresponding control group.

Table 1. Demographic data

\begin{tabular}{|c|c|c|c|c|c|c|}
\hline & Dexmedetomidine group & $C_{D}$ group & Midazolam group & $C_{M}$ group & Propofol group & $C_{P}$ group \\
\hline Total injected dose $(\mathrm{mg} / \mathrm{kg})$ & 0.4 & - & 50 & - & 26 & - \\
\hline LORR induction time (sec) & $2310 \pm 612[2100(1845-2400)]$ & - & $24 \pm 84[0(0-300)]$ & - & Immediately [0 (0-0)] & - \\
\hline LORR duration (sec) & $10470 \pm 3864[11700(9960-12675)]$ & - & $1116 \pm 210[870(570-1200)]$ & - & $300 \pm 144[240(210-287.3)]$ & - \\
\hline
\end{tabular}

All values are means \pm standard deviation [median (25\%-75\%)]. Abbreviations: $C_{D}$ group, corresponding control group for the dexmedetomidine group; $C_{M}$ group, corresponding control group for midazolam; $\mathrm{C}_{\mathrm{p}}$ group, corresponding control group for propofol; LORR, loss of righting reflex.

No significant group difference in immune cell apoptosis was observed, except for $\mathrm{CD}^{+} \mathrm{T}$ cells, in any of the three intravenous anesthetic agent groups and the corresponding control groups (Figure 2). Apoptosis of $\mathrm{CD}^{+} \mathrm{T}$ cells from PBMCs was signifi- cantly more frequent in the dexmedetomidine and propofol groups, compared with the corresponding control groups [ $8.15 \pm 3.74 \%$ in the dexmedetomidine group vs. $3.62 \pm 2.19 \%$ in the $C_{D}$ group, $p<0.05 ; 23.77$ 
$\pm 10.27 \%$ in the propofol group vs. $4.74 \pm 3.32 \%$ in the $\mathrm{C}_{\mathrm{p}}$ group, $p<0.05$ ] (Figure 2).

The histopathological findings in the liver and kidneys did not reveal any differences in the three intravenous anesthetic groups versus their corresponding control groups (Figure 3).

Immunohistochemical examinations of the dexmedetomidine and propofol groups revealed significantly lower TLR4 expression in the liver [30.11 \pm 3.57 in the dexmedetomidine group vs. $35.06 \pm 4.11$

A
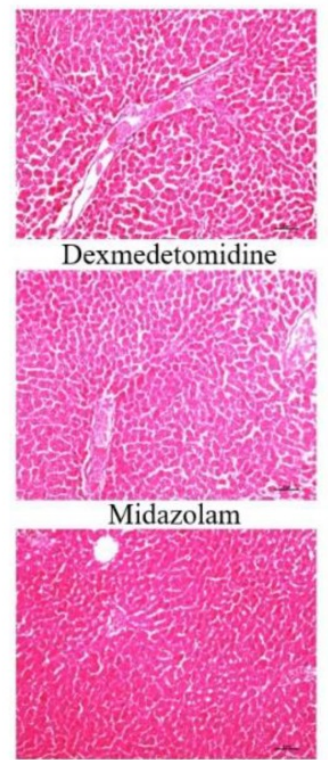

Propofol

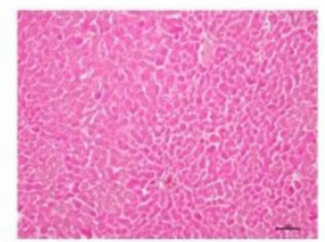

$\mathrm{C}_{\mathrm{D}}$
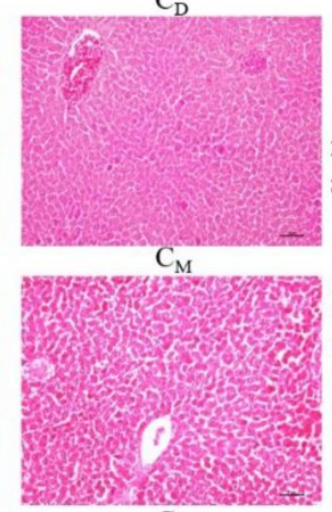

$\mathrm{C}_{\mathrm{P}}$
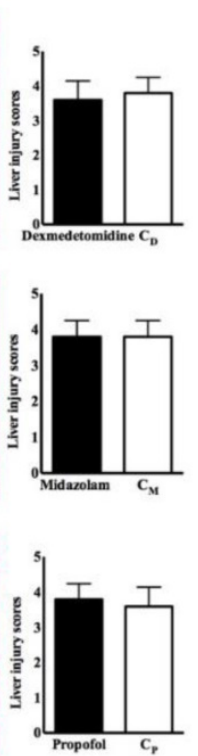

Figure 3. Liver and kidney injury scores. (A) Liver, (B) kidney. Abbreviations: $C_{D}$ group, corresponding control group for dexmedetomidine; $C_{M}$ group, corresponding control group for midazolam; $C_{p}$ group, corresponding control group for propofol.

A
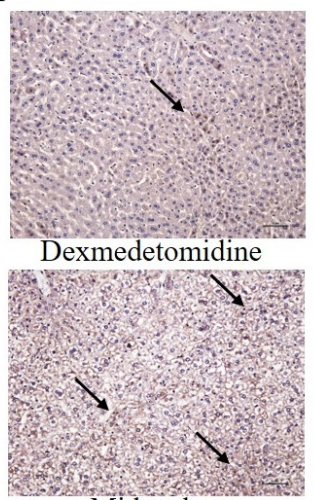

Midazolam

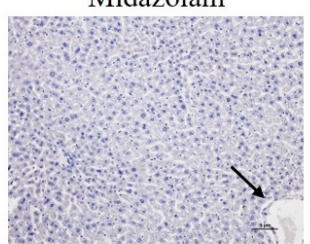

Propofol
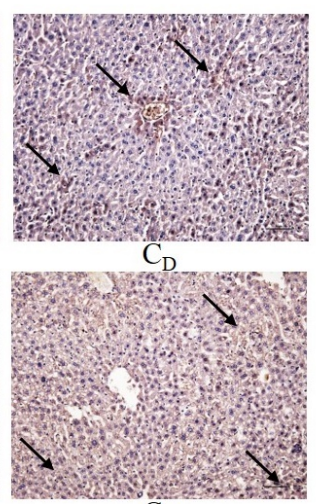

$\mathrm{C}_{\mathrm{M}}$

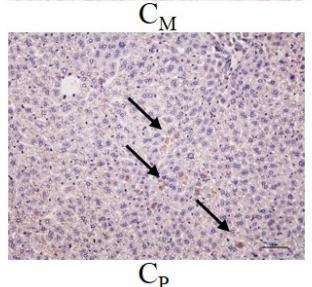

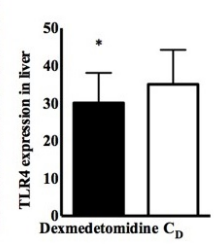
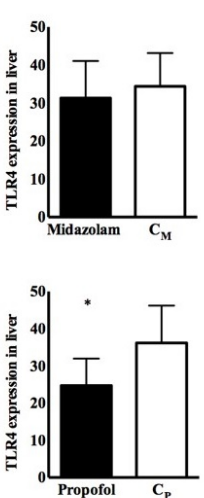

$\mathrm{B}$

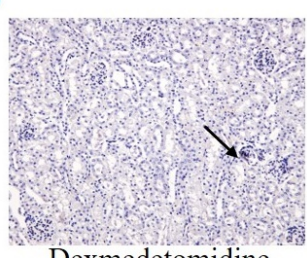

Dexmedetomidine
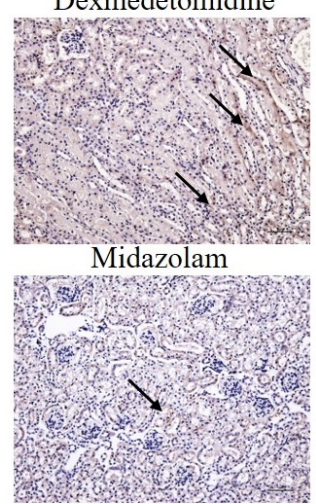

Propofol

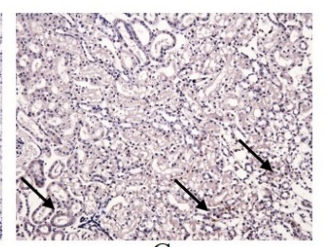

$\mathrm{C}_{\mathrm{D}}$

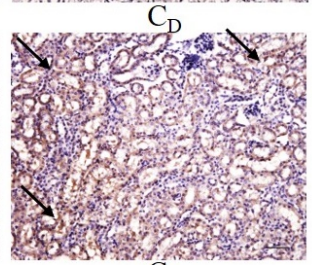

$\mathrm{C}_{\mathrm{M}}$

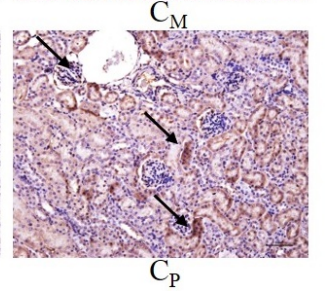

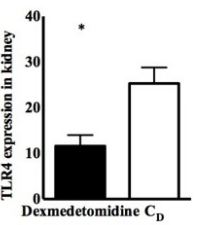
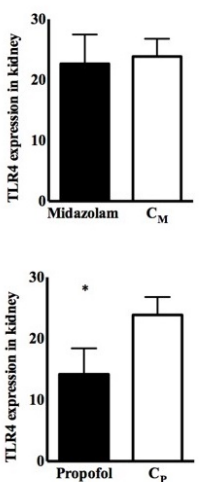

Figure 4. Toll-like receptor-4 (TLR4) expression in liver and kidney. (A) Liver, (B) kidney. Abbreviations: $C_{D}$ group, corresponding control group for dexmedetomidine; $C_{M}$ group, corresponding control group for midazolam; $C_{p}$ group, corresponding control group for propofol. Black arrow indicates TLR-4 expression. * $p<$ 0.05 compared with corresponding control group. 
Table 2. Serum cytokine levels

\begin{tabular}{|c|c|c|c|c|c|c|c|c|c|}
\hline & $\begin{array}{l}\text { Dexmedetomidine } \\
\text { group }\end{array}$ & CD group & $p$-value & Midazolam group & CM group & $p$-value & Propofol group & $\mathrm{CP}$ group & $p$-value \\
\hline $\begin{array}{l}\text { IL-2 } \\
\text { (ng/ml) }\end{array}$ & $\begin{array}{l}9.22 \pm 1.34 \\
{[10.22(7.67-11.30)]}\end{array}$ & $\begin{array}{l}10.76 \pm 2.50 \\
{[11.25(8.55-12.38)]}\end{array}$ & 0.42 & $\begin{array}{l}11.28 \pm 2.18 \\
{[10.69(10.40-13.87)]}\end{array}$ & $\begin{array}{l}10.68 \pm 3.95 \\
{[9.55(8.25-11.08)]}\end{array}$ & 0.15 & $\begin{array}{l}12.12 \pm 3.40 \\
{[12.56(9.87-14.24)]}\end{array}$ & $\begin{array}{l}11.94 \pm 2.54 \\
{[12.36(9.75-13.39)]}\end{array}$ & 0.69 \\
\hline $\begin{array}{l}\text { IFN-ץ } \\
(\mathrm{ng} / \mathrm{ml})\end{array}$ & $\begin{array}{l}16.46 \pm 3.20 \\
{[17.52(14.75-18.72)]}\end{array}$ & $\begin{array}{l}15.29 \pm 2.44 \\
{[16.28(14.64-17.73)]}\end{array}$ & 0.42 & $\begin{array}{l}13.90 \pm 2.83 \\
{[13.25(11.75-14.73)]}\end{array}$ & $\begin{array}{l}14.88 \pm 3.50 \\
{[13.56(12.22-17.75)]}\end{array}$ & 0.69 & $\begin{array}{l}13.48 \pm 2.58 \\
{[12.35(12.29-15.75)]}\end{array}$ & $\begin{array}{l}13.90 \pm 3.56 \\
{[13.56(10.74-17.75)]}\end{array}$ & 0.99 \\
\hline $\begin{array}{l}\text { TNF-a } \\
(\mathrm{pg} / \mathrm{ml})\end{array}$ & $\begin{array}{l}23.11 \pm 4.22 \\
{[23.26(19.74-25.96)]}\end{array}$ & $\begin{array}{l}27.38 \pm 5.22 \\
{[25.26(24.00-30.62)]}\end{array}$ & 0.06 & $\begin{array}{l}25.37 \pm 2.36 \\
{[24.65(20.83-27.26)]}\end{array}$ & $\begin{array}{l}23.85 \pm 3.94 \\
{[24.33(19.91-27.15)]}\end{array}$ & 0.84 & $\begin{array}{l}27.22 \pm 3.45 \\
{[29.48(22.93-30.95)]}\end{array}$ & $\begin{array}{l}26.33 \pm 4.85 \\
{[25.98(22.63-30.87)]}\end{array}$ & 0.99 \\
\hline $\begin{array}{l}\text { TGF- } \beta \\
(\mathrm{pg} / \mathrm{ml})\end{array}$ & $\begin{array}{l}12.44 \pm 2.34 \\
{[11.56(10.30-13.58)]}\end{array}$ & $\begin{array}{l}13.42 \pm 1.34 \\
{[13.69(12.44-14.83)]}\end{array}$ & 0.10 & $\begin{array}{l}9.63 \pm 1.52 \\
{[10.33(8.23-10.69)]}\end{array}$ & $\begin{array}{l}11.83 \pm 4.00 \\
{[10.11(8.74-15.29)]}\end{array}$ & 0.84 & $\begin{array}{l}13.82 \pm 1.74 \\
{[13.56(11.70-14.45)]}\end{array}$ & $\begin{array}{l}12.34 \pm 2.77 \\
{[11.56(11.09-13.24)]}\end{array}$ & 0.42 \\
\hline
\end{tabular}

\section{Discussion}

This study showed that repetitive exposure to dexmedetomidine and propofol reduced the expression of $\mathrm{CD}^{+} \mathrm{T}$ cells in the serum, and the intensity of TLR4 expression in the liver and kidneys, with increased apoptosis in PBMCs. However, repetitive exposure to the three intravenous anesthetic agents did not result in any liver or kidney injuries with increasing cytokine levels.

There have been numerous studies for the effect of a specific intravenous anesthetic agent on the mechanism of immune response under a specific condition. However, the studies with a single injection or continuous infusion, not repetitive injection, of intravenous anesthetic agent have been conducted without any control group. The procedure under repetitive injection of intravenous anesthetic agent is very common in clinical situation. Therefore, the aim in the present study was to confirm the effect of repetitive exposure to intravenous anesthetic agent on immunity.

The significant differences in induction time and duration of LORR among the three intravenous anesthetic agents in the present study could be explained by their different pharmacokinetic and pharmacodynamic properties. Direct comparison among the three intravenous anesthetic agents was impossible. Therefore, we determined the maximal doses for sedation based on literature studies and compared them with the corresponding control groups (15-18). If a more objective surrogate for pharmacodynamics than LORR, such as electroencephalograph-based devices, was applied with the various doses of intravenous anesthetic agents used in the present study, a dose-response relationship could be derived and could give more information about immunity.

The present study showed different expression patterns of immune cells among intravenous anesthetic agents, suggesting that the agents have unique effects on the immunity. Repetitive exposure to dexmedetomidine and propofol reduced the expression of $\mathrm{CD} 4^{+} \mathrm{T}$ cells with increased apoptosis of
PBMCs, indicating an immunosuppressive effect or protective effect against injury. This finding was supported by the lower expression of TLR4 in the liver and kidneys. However, no differences in cytokines were seen. Therefore, functional data for viable immune cells in the present study would be helpful. Wang et al. (19) reported that dexmedetomidine attenuated $\mathrm{CD}^{+} \mathrm{T}$ cells and restrained the phosphorylation of nuclear factor kappa-light-chainenhancer of activated B cells (NF-kB), participating in the regulation of cytokine secretion in mice with hepatitis. Many studies have demonstrated that dexmedetomidine has a protective effect against injury through TLR4, with or without a reduction in cytokine levels (20-24). Propofol had a similar effect on immune cells and TLR4 expression. Although propofol increased the expression of immune cells compared with inhaled anesthetic agents, it significantly increased the apoptosis of lipopolysaccharidetreated mononuclear cells and lymphocytes (25-27). Many studies have supported a protective effect of propofol against injury through TLR4 (28-32). The difference in results between propofol and midazolam in the present study was remarkable, although both are GABAergic drugs. Sedation from intravenous anesthetic agents can indirectly modulate the immunity, and intravenous anesthetic agents can directly affect the immunity. GABAergic drugs, including propofol and midazolam, are reported to have immune modulating effects (33). However, Yuki et al. (34) reported that propofol suppresses $\mathrm{T}$ cell proliferation, whereas midazolam does not. Midazolam also has a protective effect against injury; however, this is not due to direct modulation of immune cells, but rather a direct effect on target cells (35).

The protective effect of intravenous anesthetic agents with a short duration on the liver and kidneys would be associated with non-specific histopathologic findings (36-38).

Only CD4 ${ }^{+} \mathrm{T}$ cells among the immune cells in the present study were affected by dexmedetomidine and propofol, in association with time elapsed. The immune response usually occurs following particular 
steps. The innate immune response, including of neutrophils, protects against injury (40). The maximal activity of neutrophils occurs 1-3 days after an injury. Signals from the innate immune response activate the acquired immune response. The maximal activity of $\mathrm{T}$ cells occurs 5 days after injury. Most studies investigated the immunity within 5 days after a single injection of an intravenous anesthetic agent under specific conditions (39-42). However, the immunity in the present study was checked 5 days after daily, repeated administration of the intravenous anesthetic agents. Therefore, the results of the present study would be different from previous reports. Moreover, we did not induce any injury before repetitive administration.

In the present study, $\mathrm{CD} 4^{+} \mathrm{T}$ cell apoptosis was increased significantly in the dexmedetomidine and propofol groups compared with the corresponding control groups. Clinical trials of the effect of intravenous anesthetic agents on lymphocyte apoptosis are rare. Braz et al. (43) reported that patients under propofol anesthesia had lower levels of oxidized purines and apoptosis of helper $\mathrm{T}$ lymphocytes. Although evidence for the association between lymphocyte apoptosis and clinical impact is limited (44), the consequences from increased lymphocyte apoptosis are expected to decrease inflammatory factors and would lead to better clinical outcomes.

The immune response protects the host against pathogens. However, an excessive immune response can result in tissue injury. Therefore, a balance in the immune response is critical to maintain homeostasis. The choice of dexmedetomidine and propofol is helpful for patients requiring repetitive sedation who develop an excessive immune response, such as an autoimmune disease or hypersensitivity.

Several considerations in the present study should be discussed. First, emulsified propofol in dilution with normal saline, not pure propofol, was used in the present study. Also, the control group for propofol was tested with normal saline, not emulsifier. To check the effect of propofol on the immunity of mice, pure propofol in dilution with emulsifier and emulsifier as a control should be compared. However, propofol is used clinically with an emulsified formulation. The manufacturer of propofol recommends the use of normal saline or $5 \%$ dextrose water to dilute emulsified propofol (45). Moreover, dilution with normal saline is used to prevent pain from the injection of propofol (46). Second, the immunity after repetitive exposure to intravenous anesthetic agents would be transient and have less impact on the host. However, the impact in patients with immune disorders would be substantial and should be considered in situations involving repetitive exposure to intravenous anesthetic agents, although further evaluation is required to confirm this. Third, experiments on the effect of intravenous anesthetic agents on specific conditions such as immune-activated conditions, using lipopolysaccharide, support the results of the present study. However, the specific condition itself might influence the intravenous anesthetic agent-related immunity. Therefore, we performed our experiment in the absence of any specific disease to clarify the effect of the intravenous anesthetic agent itself on the immunity of the mice.

In conclusion, intravenous anesthetic agents for sedation should be chosen based on their pharmacokinetic and pharmacodynamic properties. Repetitive exposure to all three intravenous anesthetic agents in this study had no effect on liver and kidney injury, although dexmedetomidine and propofol reduced the expression of $\mathrm{CD}^{+} \mathrm{T}$ cells, and the intensity of TLR4 in liver and kidney with increased apoptosis in PBMCs.

\section{Acknowledgements}

This research was supported by Hana Pharm. This research was supported by Basic Science Research Program through the National Research Foundation of Korea (NRF) funded by the Ministry of Education (NRF-2018R1D1A1B07047066). This study was supported by the National Research Foundation of Korea (NRF) grant funded by the Korea government (NRF-2016R1A5A2012284). This study was presented as a poster in International Meeting 2017 for Korean Association of Immunology.

\section{Author Contributions}

All authors read and accepted Terms and Conditions of International Journal of Medical Sciences. Hyun Jun Park: data collection, data analysis and interpretation, manuscript composition. Liyun Piao: data collection, data analysis and interpretation. Eun-Hye Seo, Ph.D.: data collection, data analysis and interpretation, manuscript composition. Seung Hyun Lee, M.D., Ph.D.: data collection, data analysis and interpretation, manuscript composition. Seong-Hyop Kim, M.D., Ph.D.: study design, data collection, data analysis and interpretation, manuscript composition.

\section{Competing Interests}

The authors have declared that no competing interest exists.

\section{References}

1. Weerink MAS, Struys MMRF, Hannivoort LN, Barends CRM, Absalom AR, Colin P. Clinical Pharmacokinetics and Pharmacodynamics of Dexmedetomidine. Clinical Pharmacokinetics 2017;56:893-913.

2. Mohammadi B, Haeseler G, Leuwer M, Dengler R, Krampfl K, Bufler J. Structural requirements of phenol derivatives for direct activation of chloride 
currents via GABAA receptors. European Journal of Pharmacology 2001;421:85-91.

3. Reiner GN, Delgado-Marín L, Olguín N, Sánchez-Redondo S, Sánchez-Borzone M, Rodríguez-Farré E, Suñol C, García DA. Gabaergic Pharmacological Activity of Propofol Related Compounds as Possible Enhancers of General Anesthetics and Interaction with Membranes. Cell Biochemistry and Biophysics 2013;67:515-525.

4. Álvaro-Bartolomé M, Salort G, García-Sevilla JA. Disruption of brain MEK-ERK sequential phosphorylation and activation during midazolam-induced hypnosis in mice: Roles of GABAA receptor, MEK1 inactivation, and phosphatase MKP-3. Progress in Neuro-Psychopharmacology $\mathcal{E}$ Biological Psychiatry 2017;75:84-93.

5. Jang Y, Yeom MY, Kang ES, Kang JW, Song HK. The antinociceptive effect of dexmedetomidine modulates spleen cell immunity in mice. International Journal of Medical Sciences 2014;11:226-233.

6. Ferreira JA, Bissell BD. Misdirected Sympathy: The Role of Sympatholysis in Sepsis and Septic Shock. Journal of Intensive Care Medicine 2018;33:74-86.

7. Wu C, Qin X, Du H, Li N, Ren W, Peng Y. The immunological function of GABAergic system. Frontiers in Bioscience 2017;22:1162-1172.

8. Barragan A, Weidner JM, Jin Z, Korpi ER, Birnir B. GABAergic signalling in the immune system. Acta Physiologica 2015;213:819-827.

9. Jin Z, Mendu SK, Birnir B. GABA is an effective immunomodulatory molecule. Amino Acids 2013;45:87-94.

10. Sanders RD, Hussell T, Maze M. Sedation \& immunomodulation. Anesthesiology Clinics 2011;29:687-706.

11. Vakkuri A, Yli-Hankala A, Talja P, Mustola S, Tolvanen-Laakso H, Sampson T, Viertiö-Oja H. Time-frequency balanced spectral entropy as a measure of anesthetic drug effect in central nervous system during sevoflurane, propofol, and thiopental anesthesia. Acta Anaesthesiol Scand 2004;48:145-153.

12. Schläppi B. Safety aspects of midazolam. Br J Clin Pharmacol 1983;16 Suppl 1:37S-41S

13. Holland AJ. Laboratory animal anaesthesia. Can Anaesth Soc J 1973;20:693-705.

14. Tremoleda JL, Kerton A, Gsell W. Anaesthesia and physiological monitoring during in vivo imaging of laboratory rodents: considerations on experimental outcomes and animal welfare. EJNMMI Res 2012;2:44.

15. Cruz JI. Anesthesia in experimental animals. Basic principles. Rev Esp Anestesiol Reanim 1996;43:99-107.

16. Gargiulo S, Greco A, Gramanzini M, Esposito S, Affuso A, Brunetti A, Vesce G. Mice anesthesia, analgesia, and care, Part I: anesthetic considerations in preclinical research. ILAR journal 2012;53:E55-E69.

17. de Jong $\mathrm{RH}$, Bonin JD. Benzodiazepines protect mice from local anesthetic convulsions and deaths. Anesthesia \& Analgesia 1981;60:385-389.

18. Garfield JM, Bukusoglu C. Propofol and Ethanol Produce Additive Hypnotic and Anesthetic Effects in the Mouse. Anesthesia \& Analgesia 1996;83:156-161.

19. Wang $\mathrm{H}, \mathrm{Hu}$ B, Zou Y, Bo L, Wang J, Li J, Luo Y. Dexmedetomidine premedication attenuates concanavalin A-induced hepatitis in mice. J Toxicol Sci 2014;39:755-764.

20. Yao H, Chi X, Jin Y, Wang Y, Huang P, Wu S, Xia Z, Cai J. Dexmedetomidine Inhibits TLR4/NF-kappaB Activation and Reduces Acute Kidney Injury after Orthotopic Autologous Liver Transplantation in Rats. Sci Rep 2015;5:16849.

21. Zhang J, Wang Z, Wang Y, Zhou G, Li H. The effect of dexmedetomidine on inflammatory response of septic rats. BMC Anesthesiol 2015;15:68.

22. Yang YF, Peng K, Liu H, Meng XW, Zhang JJ, Ji FH. Dexmedetomidine preconditioning for myocardial protection in ischaemia-reperfusion injury in rats by downregulation of the high mobility group box 1-toll-like receptor 4-nuclear factor kappaB signalling pathway. Clin Exp Pharmacol Physiol 2017;44:353-361.

23. Meng L, Li L, Lu S, Li K, Su Z, Wang Y, Fan X, Li X, Zhao G. The protective effect of dexmedetomidine on LPS-induced acute lung injury through the HMGB1-mediated TLR4/NF-kB and PI3K/Akt/mTOR pathways. Molecular Immunology 2018;94:7-17.

24. Wang SL, Duan L, Xia B1, Liu Z, Wang Y, Wang GM. Dexmedetomidine preconditioning plays a neuroprotective role and suppresses TLR4/NF-KB pathways model of cerebral ischemia reperfusion. Biomedicine $\mathcal{E}$ Pharmacotherapy 2017;93:1337-1342.

25. Wang F, Li H, Shi H, Sun B. Pro-apoptotic role of nuclear factor-kappaB in adriamycin-induced acute myocardial injury in rats. Mol Med Rep 2012;5:400-404.

26. Ma L, Wu XY, Zhang LH, Chen WM, Uchiyama A, Mashimo T, Fujino $Y$. Propofol exerts anti-inflammatory effects in rats with lipopolysaccharide-induced acute lung injury by inhibition of CD14 and TLR4 expression. Braz J Med Biol Res 2013;46:299-305.

27. Ren XF, Li WZ, Meng FY, Lin CF. Differential effects of propofol and isoflurane on the activation of T-helper cells in lung cancer patients. Anaesthesia 2010;65:478-482.

28. Zhang Q, Sun P, Zhang S, Tian Y, Zhang J. Effects of propofol on the mRNA expression of toll-like receptor 4 in BV-2 cells during mimic ischemia-reperfusion injury in vitro. J Huazhong Univ Sci Technolog Med Sci 2008;28:711-713.

29. Ma L, Yang Y, Sun X, Jiang M, Ma Y, Yang X, Guo Z. Propofol regulates the expression of TLR4 through miR-21 in human umbilical vein endothelial cells. Molecular Medicine Reports 2017;16:9074-9080.

30. Wu GJ, Lin YW, Chuang CY, Tsai HC, Chen RM. Liver nitrosation and inflammation in septic rats were suppressed by propofol via downregulating
TLR4/NF-kB-mediated iNOS and IL-6 gene expressions. Life Sciences 2018;195:25-32

31. Liu W, Zhu H, Fang H. Propofol Potentiates Sevoflurane-Induced Inhibition of Nuclear Factor--kB-Mediated Inflammatory Responses and Regulation of Mitogen-Activated Protein Kinases Pathways via Toll-like Receptor 4 Signaling in Lipopolysaccharide-Induced Acute Lung Injury in Mice. The American Journal of the Medical Sciences 2017;354:493-505.

32. Qin X, Sun ZQ, Zhang XW, Dai XJ, Mao SS, Zhang YM. TLR4 signaling is involved in the protective effect of propofol in BV2 microglia against OGD/reoxygenation. Journal of Physiology and Biochemistry 2013;69:707-718.

33. Prud'homme GJ, Glinka Y, Wang Q. Immunological GABAergic interactions and therapeutic applications in autoimmune diseases. Autoimmunity Reviews 2015;14:1048-1056.

34. Yuki K, Soriano SG, Shimaoka M. Sedative drug modulates T-cell and lymphocyte function-associated antigen-1 function. Anesth Analg 2011;112:830-838.

35. Ohta N, Ohashi Y, Takayama C, Mashimo T, Fujino Y. Midazolam suppresses maturation of murine dendritic cells and priming of lipopolysaccharide-induced $t$ helper 1-type immune response. Anesthesiology 2011;114:355-362.

36. Feng J, Yao W, Zhang Y, Xiang AP, Yuan D, Hei Z. Intravenous Anesthetics Enhance the Ability of Human Bone Marrow-Derived Mesenchymal Stem Cells to Alleviate Hepatic Ischemia-Reperfusion Injury in a Receptor-Dependent Manner. Cellular Physiology and Biochemistry 2018;47:556-566.

37. Liu Y, Sheng B, Wang S, Lu F, Zhen J, Chen W. Dexmedetomidine prevents acute kidney injury after adult cardiac surgery: a meta-analysis of randomized controlled trials. BMC Anesthesiology 2018:18:7.

38. Leite TT, Macedo E, Martins Ida S, Neves FM, Libório AB. Renal Outcomes in Critically Ill Patients Receiving Propofol or Midazolam. Clinical Journal of the American Society of Nephrology 2015;10:1937-1945.

39. Iwasaki A, Pillai PS. Innate immunity to influenza virus infection. Nat Rev Immunol 2014;14:315-328

40. Zmora N, Bashiardes S, Levy M, Elinav E. Maayan Levy, EranElinav. The Role of the Immune System in Metabolic Health and Disease. Cell Metab 2017;25:506-521.

41. Poletaev A, Boura P. The immune system, natural autoantibodies and general homeostasis in health and disease. Hippokratia 2011:15:295-298

42. Dudley DJ. The immune system in health and disease. Baillieres Clin Obstet Gynaecol 1992;6:393-416.

43. Braz MG, Braz LG, Mazoti MA, Pinotti MF, Pardini MI, Braz JR, Salvadori DM. Lower levels of oxidative DNA damage and apoptosis in lymphocytes from patients undergoing surgery with propofol anesthesia. Environmental and Molecular Mutagenesis 2012;53:70-77.

44. Cassinello F, Prieto I, del Olmo M, Rivas S, Strichartz GR. Cancer surgery: how may anesthesia influence outcome? Journal of Clinical Anesthesia 2015;27:262-272.

45. [Internet] Product information for Anepol inj. <http://www.hanaph.co.kr/product/productList.do>

46. Aggarwal S, Kumar M, Sharma V. A single-centre randomized-controlled trial to study effect of dilution on propofol-induced injection pain at injection site. Saudi Journal of Anaesthesia 2011;5:282-285. 